\title{
Intra-aortic balloon pumping in children undergoing cardiac surgery: An update of the Liverpool experience
}

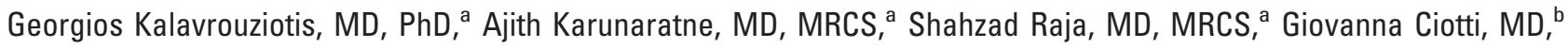
Manoj Purohit, MD, FRCS, ${ }^{a}$ Antonio F. Corno, MD, PhD, FRCS, FECTS, FAATS, ${ }^{a}$ and Marco Pozzi, MD, FRCS, FECTS ${ }^{a}$

Supplemental material is available online.
From the Departments of Pediatric CardioThoracic Surgery a and Pediatric Cardiology, ${ }^{\text {b }}$ Royal Liverpool Children's NHS Trust, Alder Hey Hospital, Liverpool, United Kingdom.

Received for publication Dec 5, 2005; revisions received Feb 19, 2006; accepted for publication Feb 24, 2006.

Address for reprints: Georgios Kalavrouziotis, $\mathrm{MD}, \mathrm{PhD}$, Royal Liverpool Children's Hospital, Pediatric Cardio-thoracic Surgery, Eaton Rd, Liverpool L12 2AP, United Kingdom (E-mail: gkalavrouziotis@yahoo.com).

J Thorac Cardiovasc Surg 2006;131:1382-89 $0022-5223 / \$ 32.00$

Copyright $(\odot) 2006$ by The American Association for Thoracic Surgery

doi:10.1016/j.jtcvs.2006.02.016
Objective: Intra-aortic balloon pumping in children remains a rarity. We report our experience in supporting pediatric cardiac surgical patients with intra-aortic balloon pumping.

Methods: We reviewed the cases of 24 children supported with intra-aortic balloon pumping after cardiac surgery in our institution from 1994 through 2003.

Results: Mean age at the time of the operation was $5.0 \pm 5.6$ years (range, 7 days-17.5 years). Ten patients were infants less than 6 months old. Mean weight was $18.9 \pm 18.1 \mathrm{~kg}$ (range, 3.5-58.7 kg). Indications for intra-aortic balloon pump deployment were postoperative hemodynamic deterioration ( $\mathrm{n}=11,8$ survivors), failure to wean off cardiopu( $\mathrm{n}=7,5$ survivors), and prophylaxis before weaning off cardiopulmonary bypass ( $\mathrm{n}=6,5$ survivors). The balloon was inserted through the ascending aorta in infants and through the femoral artery in children. Eighteen children ( 7 infants) were weaned off the intra-aortic balloon pump successfully (intra-aortic balloon pump survival, 75\%). Mean duration of intra-aortic balloon pump support was $121.3 \pm 140.60$ hours (range, 8-670 hours). There were 3 post-intra-aortic balloon pump in-hospital deaths (survival to hospital discharge, $62.5 \%$ ). Severe intra-aortic balloon pump-related complications were mesenteric ischemia in 1 patient and lower limb ischemia requiring intra-aortic balloon pump removal in 1 patient. At a mean follow-up of $85 \pm 31$ months (range, 18-124 months), all 15 long-term survivors were alive and well.

Conclusions: Use of an intra-aortic balloon pump is an effective modality of cardiac support in properly selected pediatric cardiac surgical patients with refractory low cardiac output. It can be safely used in small infants and neonates. In selected cases with known left ventricular dysfunction, there is a place for prophylactic use of an intra-aortic balloon pump.

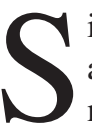
ince its invention and introduction in clinical practice in the $1960 \mathrm{~s},{ }^{1}$ intraaortic balloon pumping (IABP) has been a well-established mode of treatment for acute low cardiac output syndrome and cardiogenic shock after myocardial infarction or cardiac surgery in adults. ${ }^{2}$ However, its use in children remains a rarity. Pollock and colleagues, ${ }^{3}$ who first described the use of IABP in children in 1980 , reported $80 \%$ survival in children older than 10 years but no survival in children younger than 5 years. The use of balloons of inappropriate size and "greater aortic elasticity" were thought to be the main culprits for the unsatisfactory results in children.

Our institution does not have an extracorporeal membrane oxygenation (ECMO) or ventricular assist device (VAD) program. Therefore we have used prolonged conventional cardiopulmonary bypass $(\mathrm{CPB})^{4}$ and, since 1994, IABP for cardiac support in children. Our initial experience (1994-1997) with 14 pediatric surgical patients supported with IABP has been published. ${ }^{5}$ The present report summarizes 


$$
\begin{aligned}
& \text { Abbreviations and Acronyms } \\
& \begin{aligned}
\text { ALCAPA }= & \text { anomalous left coronary artery originated } \\
& \text { from the pulmonary artery } \\
\text { BW } & =\text { body weight } \\
\text { CPB } & =\text { cardiopulmonary bypass } \\
\text { ECG } & =\text { electrocardiogram } \\
\text { ECMO } & =\text { extracorporeal membrane oxygenation } \\
\text { IAB } & =\text { intra-aortic balloon } \\
\text { IABP } & =\text { intra-aortic balloon pumping } \\
\text { ICU } & =\text { intensive care unit } \\
\text { LV } & =\text { left ventricular } \\
\text { PS } & =\text { pulmonary stenosis } \\
\text { VAD } & =\text { ventricular assist device }
\end{aligned}
\end{aligned}
$$

the 10-year experience of our institution in the use of IABP in children undergoing cardiac surgery.

\section{Patients and Methods}

We reviewed the medical records of all patients who were supported with IABP at the Royal Liverpool Children's NHS Trust, Alder Hey Hospital, Liverpool, United Kingdom, from August 1994 through December 2003. During this period, 2834 children underwent cardiac surgery in our institute; of these, $24(0.84 \%)$ required IABP. One nonsurgical patient with dilated cardiomyopathy who received IABP was excluded from the study. Each patient's medical record was reviewed for age, body weight (BW), diagnosis, operation or operations, inotropic support, indications and timing of IABP deployment, duration of support, mortality, and morbidity.

Age, BW, duration of IABP support, and length of stay in the intensive care unit (ICU) and hospital are expressed as mean values \pm standard deviation. Group comparisons were performed with the Student $t$ test and the $\chi^{2}$ test.

There were $14(58.3 \%)$ boys. Mean age was $5.0 \pm 5.6$ years (range, 7 days-17.5 years; median, 2.5 years). Mean BW was $18.9 \pm$ $18.1 \mathrm{~kg}$ (range, 3.5-58.7 kg; median, $12.3 \mathrm{~kg}$ ). Ten (41.7\%) children were infants (the infants group), with a mean age of $0.24 \pm 0.16$ years (range, 7 days- 6 months) and a mean BW of $4.2 \pm 0.7 \mathrm{~kg}$ (range, $3.5-5.8 \mathrm{~kg}$ ). Fourteen children were older than 22 months (the children group), with a mean age of $8.4 \pm 5.1$ years (range, 1.8-17.5 years) and a mean BW of $29.5 \pm 17.1 \mathrm{~kg}$ (range, $12-58.7 \mathrm{~kg}$ ).

The selection of the appropriate balloon catheter for our patients was based on the Datascope guidelines for pediatric balloon sizing according to age and weight (Appendix E1). ${ }^{6}$

We used a balloon volume of $2.5 \mathrm{~mL}$ in 10 patients (BW, $3.5-5.8 \mathrm{~kg}$ ), $5 \mathrm{~mL}$ in 5 patients (BW, $12-15.2 \mathrm{~kg}$ ), $7 \mathrm{~mL}$ in 1 patient (BW, $18 \mathrm{~kg}$ ), $12 \mathrm{~mL}$ in 3 patients (BW, 21.7-33 kg), and $34 \mathrm{~mL}$ in 5 patients (BW, 44-58.7 kg).

\section{Indications and Timing of IABP Deployment}

All 24 patients underwent cardiac surgery for congenital heart diseases (diagnoses and operations are summarized in Table 1). They were mechanically ventilated and receiving inotropic support at the time of IABP deployment with enoximone $(\mathrm{n}=24,100 \%)$, dobutamine ( $\mathrm{n}=22,91.6 \%)$, adrenaline $(\mathrm{n}=14,58.3 \%)$, dopa- mine $(\mathrm{n}=6,25 \%)$, noradrenaline $(\mathrm{n}=3,12.5 \%)$, and vasopressin $(\mathrm{n}=2,8 \%)$. We consider adrenaline requirements greater than $0.05 \mu \mathrm{g} \cdot \mathrm{kg}^{-1} \cdot \mathrm{min}^{-1}$ as a strong indication for initiating IABP.

General indications for IABP use in our institution are a patient in a low cardiac output state (hypotension, persistent metabolic acidosis, low urine output, and clinical evidence of poor peripheral perfusion) that seems reversible, who had an optimal surgical correction of his or her heart defect and is receiving maximum pharmacologic support. Patients in a moribund condition or with a terminal illness, severe neurologic damage, sepsis, irreparable heart lesion, or moderate-to-severe aortic valve regurgitation are not considered eligible for IABP. In 13 (54.2\%) patients IABP was initiated in the theater, whereas in 11 patients it started in the ICU (Table 2). Indications for IABP deployment were as follows:

1. Failure to wean off $\mathrm{CPB}$ in 8 cases: One infant with anomalous origin of both coronaries from the pulmonary artery continued receiving conventional CPB for circulatory support for 154 hours before IABP insertion.

2. Prophylaxis in 5 patients in whom IABP was started before any attempt to wean off CPB: They all had preoperatively known poor left ventricular (LV) function caused by aortic stenosis $(n=1)$ or anomalous left coronary artery originating from the pulmonary artery (ALCAPA; $n=4$ ).

3. Hemodynamic deterioration postoperatively in 11 patients, within 24 hours in 7 patients, and within 36 hours in 3 patients after admission in the ICU: The 11th patient (a neonate after an arterial switch operation) had cardiac arrest 5 hours after his arrival in the ICU. He was transferred back to the theater and started on conventional CPB. After 48 hours of circulatory support with CPB, IABP was deployed for 670 hours, with an excellent outcome (long-term survivor).

\section{Site and Technique of Intra-aortic Balloon Insertion}

The intra-aortic balloon (IAB) catheters were inserted (1) in 13 children through the common femoral artery (right, 8 ; left, 5) by means of direct cut-down to the artery, where the balloon was introduced either directly $(\mathrm{n}=10)$ or through a short sleeve of a 5-mm polytetrafluoroethylene graft anastomosed end to side to the femoral artery $(\mathrm{n}=3)$, or (2) in all 10 infants and in the smallest child in our series (22-month-old; BW, $12 \mathrm{~kg}$ ) through the ascending aorta antegradely through either the cardioplegia $(n=7)$ or the arterial cannula $(n=2)$ or a separate purse-string site at the ascending aorta $(n=2)$. The length of the IAB catheter was premeasured on the child, and the estimated length was marked with a ligature. In neonates we removed the guide wire before advancing the catheter downward to the descending aorta because it is guided safer and easier. The catheter was secured in place with the purse-string suture, which was secured by a plastic snugger fixed with multiple metal clips. The sternum was left open and stented in all 11 patients. The skin incision was covered with a silicone elastomer membrane. The IAB catheter exited the chest underneath the silicone membrane and was fixed to the skin before being connected to the pumping console. Particular attention was paid to make sure that there was no tension to the IABP catheter. In all cases a chest radiograph was taken to ascertain the IAB position according to standard guidelines. ${ }^{5,6}$ 
TABLE 1. Diagnosis, operation, and outcome of children supported with IABP

\begin{tabular}{|c|c|c|c|c|c|}
\hline Diagnosis & Operation & $\begin{array}{c}\text { No. of } \\
\text { patients }\end{array}$ & $\begin{array}{l}\text { Weaned off } \\
\text { IABP }\end{array}$ & $\begin{array}{l}\text { Discharged from } \\
\text { hospital }\end{array}$ & $\begin{array}{l}\text { Long-term } \\
\text { survivors }\end{array}$ \\
\hline \multicolumn{6}{|l|}{ I. Children } \\
\hline \multirow[t]{2}{*}{ Single ventricle } & Fontan & 5 & 4 & 2 & 2 \\
\hline & bidirectional Glenn & 1 & 0 & - & - \\
\hline AV/MV disease & AVR/MVR & 3 & 3 & 3 & 3 \\
\hline \multirow{2}{*}{$\begin{array}{l}\text { TOF + pulmonary } \\
\text { atresia }\end{array}$} & Biventricular correction & 1 & 1 & 1 & 1 \\
\hline & RV-PA conduit replacement & 1 & 0 & - & - \\
\hline TOF & Total correction & 1 & 1 & 1 & 1 \\
\hline LVOTO & $\begin{array}{l}\text { Resection of subvalvular } \\
\text { aortic membrane + IVS }\end{array}$ & 1 & 1 & 1 & 1 \\
\hline ASD sec & ASD closure & 1 & 1 & 1 & 1 \\
\hline Subtotal I & & 14 & $11(78.6 \%)$ & $9(64.3 \%)$ & $9(64.3 \%)$ \\
\hline \multicolumn{6}{|l|}{ II. Infants } \\
\hline \multirow[t]{2}{*}{ ALCAPA* } & Reimplantation to aorta & $5^{*}$ & 4 & 4 & 4 \\
\hline & Tunnel repair & 1 & 1 & 1 & 1 \\
\hline TGA & ASO & 2 & 1 & 1 & 1 \\
\hline $\begin{array}{l}\text { Multiple VSDs, RVOTO, } \\
\text { small RV }\end{array}$ & Bilateral Glenn & 1 & 0 & - & - \\
\hline AVSD, small LV & APW, PAB & 1 & 1 & 0 & - \\
\hline Subtotal II & & 10 & $7(70 \%)$ & $6(60 \%)$ & $6(60 \%)$ \\
\hline Total & & 24 & $18(75 \%)$ & $15(62.5 \%)$ & $9(62.5 \%)$ \\
\hline
\end{tabular}

$I A B P$, Intra-aortic balloon pumping; $A V$, aortic valve; $M V$, mitral valve; $A V R$, aortic valve replacement; $M V R$, mitral valve replacement; $T O F$, tetralogy of Fallot; $R V$, right ventricle; $P A$, pulmonary artery; $L V O T O$, left ventricular outflow tract obstruction; IVS, interventricular septum; $A S D$, atrial septal defect; $A L C A P A$, anomalous left coronary artery originating from the pulmonary artery; TGA, transposition of the great arteries; $A S O$, arterial switch operation; VSD, ventricular septal defect; RVOTO, right ventricular outflow tract obstruction; $A V S D$, atrioventricular septal defect; $L V$, left ventricle; $A P W$, aortopulmonary window; $P A B$, pulmonary artery banding. *One patient had both left and right coronary arteries originating from the pulmonary artery; he could not be weaned off intra-aortic balloon pumping.

After minimal drain losses, the patients were started on continuous heparin infusion to maintain an activated partial thromboplastin time of 1.5 to 2.5 times normal value.

\section{IABP Console}

The Datascope System 97 pumping console (Datascope Medical Co Ltd, Cambridge, United Kingdom) with a pediatric volumelimiting chamber was used in 23 patients. One patient received a 34-mL balloon, and the Datascope System 90 was used because it was the only system available at the time. Helium gas is used for balloon inflation/deflation because its low viscosity allows quick pneumatic response to rapid heart rates with short cardiac cycle time, as is the rule in children. Manual filling of the balloon is performed every 45 to 60 minutes, unlike the adult device, which runs on an automatic filling system. Balloon pump timing was triggered either by the R-wave from the electrocardiogram (ECG) or the arterial waveform (in case of arrhythmia). Balloon frequency was $1: 1$, except during the weaning process. Augmentation time required manual adjustments for heart rate changes greater than 10 beats/min to obtain optimal diastolic augmentation and presystolic dip.

\section{Weaning Off IABP}

Weaning began at the physician's discretion, when hemodynamic stability was maintained (blood pressure normal for age, central venous pressure $<10 \mathrm{~mm} \mathrm{Hg}$, left atrial pressure $<10 \mathrm{~mm} \mathrm{Hg}$, urine

TABLE 2. Indications and timing of IABP deployment

\begin{tabular}{|c|c|c|c|c|}
\hline Indications & Children & Infants & Total $(\%)$ & $\begin{array}{l}\text { Weaned off } \\
\text { IABP (\%) }\end{array}$ \\
\hline Failure to wean off $\mathrm{CPB}$ & 5 & 2 & $7(29.1)$ & $5(71.4)$ \\
\hline Prophylactically (before off CPB) & 1 & 5 & $6(25)$ & $5(83.3)$ \\
\hline $\begin{array}{l}\text { Postoperative hemodynamic } \\
\text { deterioration }\end{array}$ & 8 & 3 & 11 (45.8) & $8(72.7)$ \\
\hline Total & 14 & 10 & 24 & $18(75)$ \\
\hline
\end{tabular}

$I A B P$, Intra-aortic balloon pumping; $C P B$, cardiopulmonary bypass. 
TABLE 3. Mortality of pediatric IABP

\begin{tabular}{lccc}
\hline & $\begin{array}{c}\text { Children } \\
(\mathbf{n}=\mathbf{1 4})\end{array}$ & $\begin{array}{c}\text { Infants } \\
(\mathbf{n}=\mathbf{1 0})\end{array}$ & $\begin{array}{c}\text { Total } \\
(\mathbf{n}=24)\end{array}$ \\
\hline Patients weaned off IABP & $11(78.5 \%)$ & $7(70 \%)$ & $18(75 \%)$ \\
Post-IABP in-hospital deaths & 2 & 1 & 3 \\
IABP-related deaths (mesenteric ischemia) & 1 & 0 & 1 \\
IABP survivors & $10(71.4 \%)$ & $7(70 \%)$ & $17(70.8 \%)$ \\
Early survivors (patients discharged from hospital) & $9(64.3 \%)$ & $6(60 \%)$ & $15(62.5 \%)$ \\
Long-term survivors & $9(64.3 \%)$ & $6(60 \%)$ & $15(62.5 \%)$ \\
\hline
\end{tabular}

$I A B P$, Intra-aortic balloon pumping.

output $>2 \mathrm{~mL} \cdot \mathrm{kg}^{-1} \cdot \mathrm{h}^{-1}$, periphery-to-core difference in temperature $<2^{\circ} \mathrm{C}$, and no metabolic acidosis), and inotropic support was minimal (enoximone \pm dobutamine $<5 \mu \mathrm{g} \cdot \mathrm{kg}^{-1} \cdot \min ^{-1}$ ). Twodimensional echocardiography was used to aid in the decision to wean. Improvements in the LV performance and its indices (shortening fraction and ejection fraction) were used as guidelines. The weaning procedure in our institution has been described previously. ${ }^{6}$ In brief, as a first step, the augmentation was gradually reduced to $50 \%$. If this was tolerated for 4 to 6 hours, balloon frequency was reduced from $1: 1$ to $1: 2$ for 3 to 4 hours and then to $1: 3$ for 2 to 3 hours. The weaning procedure usually took 10 to 24 hours, depending on the status of the patient.

\section{Removal of the Balloon}

In case of direct cut-down of the femoral artery, the skin incision was reopened, the balloon was removed, and the exit at the artery was closed by means of direct suturing. If a side graft was used, the balloon was removed through the graft, which was doubly ligated with clips and cut off, leaving a small stump at the site of the arterial anastomosis. In case of insertion through the ascending aorta, through the open chest, the deflated balloon was carefully removed from the ascending aorta, while the purse-string suture was tightened down, closing the entrance hole. A mattress suture was placed at the insertion site for safety.

\section{Follow-up}

All long-term survivors were followed up in the outpatient clinic with clinical examination and echocardiography.

\section{Results}

\section{Mortality}

Table 3 summarizes survival and mortality in our series. Eighteen $(75 \%)$ patients were successfully weaned off IABP. Successful weaning was $78.5 \%$ in children and $70 \%$ in infants $(P=.27)$. Age was not a risk factor for mortality after IABP support.

The mean BW of infants who died on IABP support was $3.8 \mathrm{~kg}$ and that of those who survived was $4.3 \mathrm{~kg}(P=$ .269). The mean BW of children who died on IABP support was $42.6 \mathrm{~kg}$ versus $25.9 \mathrm{~kg}$ of survivors $(P=.069)$. Hence $\mathrm{BW}$ was not a risk factor to successful weaning off IABP.

There were 2 neonates in our series (a 7-day-old and a 19-day-old) with transposition of the great arteries who had an arterial switch operation. The former patient was weaned off CPB on IABP and a strong inotropic support. He had a global LV dysfunction and died 8 hours after surgical intervention. The latter patient was supported with IABP and was successfully weaned off after 670 hours of support, becoming a long-term survivor.

Concerning the timing of IABP deployment, survival was best among patients with IABP started prophylactically in the theater before attempting to wean off CPB (5/6 [83.3\%]). The patient in this group who died despite the prophylactic insertion of an IABP (a 52-day-old female weighing $3.5 \mathrm{~kg}$ ) had both coronaries originating from the pulmonary artery and a very poor ventricular performance because of extensive myocardial infarction. She was supported for only 8 hours before she died. Survival was poorer in patients with the IABP placed in the ICU (8/11 [72.7\%]), as well as in patients who failed to wean off CPB before IABP initiation (5/7 [71.4\%]), but these differences did not reach statistical significance.

The duration of IABP support ranged from 8 to 670 hours (mean, $121.3 \pm 140.60$ hours) for the whole series. In infants the mean IABP duration was $152.7 \pm 196.39$ hours (median, 106 hours; range, 8-670 hours) and in children it was $97.3 \pm 86.70$ (median, 60 hours; range, 12-260 hours; $P=.37)$.

Patients who died on IABP support were supported for a mean of $18.8 \pm 10.55$ hours (range, 8 -36 hours), whereas survivors of IABP were supported for a mean $155.6 \pm$ 147.54 hours (range, 12-670 hours; median, 120 hours; $P=$ .001 ). Patients who died were so severely sick that there was no time for the IABP to offer any help (all died within 48 hours after the operation).

Of the 18 patients who were weaned off IABP, 3 (2 children and 1 infant) died before discharge from the hospital (short-term survivors). One child (5.3-year-old female; BW, $12.6 \mathrm{~kg}$; diagnosis: "single-ventricle physiology," atrial isomerism, common atrium, double-outlet right ventricle, transposition of the great arteries, atrioventricular septal defect, and pulmonary stenosis [PS]; status after bilateral bidirectional Glenn shunt) had completion of the 
TABLE 4. Morbidity of pediatric IABP

\begin{tabular}{|c|c|c|c|}
\hline Complications & $\begin{array}{l}\text { Children } \\
\text { (n= 14) }\end{array}$ & $\begin{array}{l}\text { Infants } \\
(n=10)\end{array}$ & Total $(n=24)$ \\
\hline IABP related & 4 & 0 & 4 \\
\hline $\begin{array}{l}\text { Lower limb ischemia, femoral } \\
\text { arterioplasty }\end{array}$ & $1(1)$ & - & $1(1)$ \\
\hline Temporary foot pulse loss & 2 & - & 2 \\
\hline Thrombocytopenia & 1 & 1 & 2 \\
\hline Hemopericardium/tamponade & 0 & $1(1)$ & $1(1)$ \\
\hline Other & 3 & 5 & 8 \\
\hline Sepsis & 2 & 1 & 3 \\
\hline SVC thrombosis & $1(1)$ & 0 & $1(1)$ \\
\hline Total complications/patients & $9 / 7(50 \%)$ & $9 / 6(60 \%)$ & $18 / 13(54.1 \%)$ \\
\hline
\end{tabular}

*The number of patients who died is shown in parentheses.

Fontan procedure and was supported for 190 hours with IABP. Five days after successful weaning, she underwent exploratory laparotomy for peritonitis caused by mesenteric infarction and ischemic colitis. Colectomy with ileostomy was performed. She was re-explored 7 days later because of peritoneal abscess and died of sepsis 34 days after successful weaning off IABP.

The second child (2.5-year-old male; BW, $14 \mathrm{~kg}$; diagnosis: tricuspid atresia, ventricular septal defect, and PS; previous modified Blalock-Taussig shunt) underwent a Fontan operation and was supported with IABP for 250 hours. He was successfully weaned off IABP but died 6 weeks later during the same hospitalization caused by extensive thrombosis of the superior vena cava and jugular veins.

The third short-term survivor was an infant (4.5-monthold male; BW, $4.5 \mathrm{~kg}$ ) with "complete atrioventricular septal defect, common atrioventricular valve, and small left ventricle" submitted to pulmonary artery banding and aortopulmonary window. He was supported with IABP for 244 hours and was successfully weaned off. His postoperative course was complicated with temporary absent foot pulse, transient arrhythmia, and respiratory infection. He died of respiratory syncytial virus infection 31 days after weaning off IABP.

\section{Morbidity}

The complications observed in our patients can be arbitrarily be divided into 3 groups (Table 4):

1. IABP-related complications ( $\mathrm{n}=4$ in 3 children): One patient (described in the "Mortality" section) had mesenteric ischemia discovered 5 days after suc- cessful weaning off IABP. The balloon should be credited for this fatal complication. Some abdominal tenderness and distension noticed 3 days after IABP removal should have alerted the attending physicians, and possibly this death could have been prevented. This patient had also loss of right foot pulses, which returned after hemodynamics improved, without any other signs of limb ischemia. Chest radiography confirmed the balloon was placed above L1. Another patient (17.5 years old, submitted to right ventricleto-pulmonary artery conduit replacement and left pulmonary artery stent dilatation) had leg ischemia after 36 hours of IABP support, necessitating IAB catheter removal, femoral arterioplasty, and leg fasciotomy. The IAB was reinserted through the contralateral femoral artery. The patient died after 24 hours as a result of low cardiac output syndrome. A third patient (16 years old) had temporary foot pulse loss with mild limb ischemia not requiring IAB removal.

2. "Heparin-related" complications: Bleeding was the most common complication, necessitating chest exploration in 3 patients ( 3 times in one of them). Hemopericardium causing tamponade was the reason for chest opening in another case. In no case was bleeding related to the IAB insertion site.

3. Other complications: Sepsis was present in 3 patients ( 2 children and 1 infant) with fever (temperature $>38.5^{\circ} \mathrm{C}$ for more than 2 days) and positive blood cultures requiring change of our standard antibiotic 
TABLE 5. Literature review of pediatric IABP

\begin{tabular}{|c|c|c|c|c|c|c|c|}
\hline Year & Author & Center & $\begin{array}{l}\text { Surgical } \\
\text { patients }\end{array}$ & Age range & BW (kg) & $\begin{array}{l}\text { Weaned off } \\
\text { IABP (\%) }\end{array}$ & $\begin{array}{c}\text { Discharged from } \\
\text { hospital (\%) }\end{array}$ \\
\hline 1980 & Pollock and coworkers ${ }^{3}$ & Toronto, Canada & 14 & $1.5-18$ y & $8-52$ & $8(57)$ & $6(42.8)$ \\
\hline 1983 & Veasy and coworkers ${ }^{8}$ & Salt Lake City, Utah & 8 & 6 wk-6.1 y & $4.2-16$ & $4(50)$ & $2(25)$ \\
\hline 1985 & Webster and Veasy ${ }^{10}$ & Salt Lake City, Utah & $16\left(18^{*}\right) \dagger$ & $5 d-11.8 y$ & $3.1-33.2$ & $7(44)$ & $4(25)$ \\
\hline 1999 & Acomea-Agyin and coworkers ${ }^{5}$ & Liverpool, United Kingdom & 14 & $7 d-13$ y & $3.5-51$ & $10(71)$ & $8(57.1)$ \\
\hline 2002 & Pinkney and coworkers ${ }^{11}$ & Salt Lake City, Utah & $16(29 *)$ & $1.7 \mathrm{~m}-18.5 \mathrm{y}$ & $4.3-56$ & $9(60)$ & $9(60)$ \\
\hline 2006 & Present series & Liverpool, United Kingdom & 24 & $7 \mathrm{~d}-17.5 \mathrm{y}$ & $3.5-58$ & $18(75)$ & $15(62.5)$ \\
\hline
\end{tabular}

*The total number of patients (surgical and medical) is shown in parentheses. †Included are the 8 patients reported by Veasy and coworkers. ${ }^{9}$

protocol. Five additional patients had fever lasting less than 2 days and without positive blood cultures. No evidence of mediastinitis occurred in the 11 patients with the IABP inserted through the ascending aorta and the chest left open.

One child had severe chronic lung disease preoperatively with multiple congenital lung bullae and postoperatively required ventilation with high-flow oscillation for hypercarbia. He had repeated loculated pneumothoraces requiring insertion of intrathoracic tubes 7 times.

One infant was given a diagnosis of a clot in the left ventricle, which was dissolved after 3 days of formal anticoagulation therapy. Another infant experienced refractory arrhythmia requiring amiodarone infusion for 2 days immediately after surgical intervention.

Renal function was compromised in no case; on the contrary, urine output greatly increased after IABP institution, and in 5 cases the peritoneal dialysis instituted before IABP was discontinued.

Eleven patients (10 infants and 1 child) had the chest left open after surgical intervention. The IABP survivors had their chests closed after 5.9 to 28 days (median, 7 days). Neither sternal wound infection nor mediastinitis was noticed in the patients with a delayed chest closure.

The IABP survivors were mechanically ventilated for a median duration of 144 hours (range, 7-1370 hours); their median ICU stay was 12 days (range, 5-67 days), and the median total hospital stay was 21 days (range, 11-127 days).

\section{Follow-up Results}

All 15 discharged patients were followed up with regular clinical and echocadiographic assessment. They have all been alive and well for a mean of 7.1 years (range, 1.7-10.3 years). All have improved to normal ventricular function. One patient, a 4.3-month-old infant with ALCAPA syndrome who underwent intrapulmonary tunnel repair (Takeuchi procedure), showed evidence of PS on the echocardiogram performed on the 81 st postoperative day. She had to undergo reoperation 5 months after the initial operation for relief of tunnel stenosis and supravalvular PS. At present (8 years after reoperation), she has persistent mild PS (pressure gradient, $30 \mathrm{~mm} \mathrm{Hg}$ ).

\section{Discussion}

IABP has been routinely used in adults with LV failure. However, its use in small children and infants has not been widespread, although today the pediatric balloon catheters and pumping consoles have been greatly evolved, there are commercially available devices suitable for even the smallest child, and the early concerns about the elasticity and distensibility of the pediatric aortic wall on the effectiveness of the counterpulsation have proved ungrounded. ${ }^{7,8}$ The major reason for this is the fact that children with congenital heart disease usually have biventricular dysfunction and impaired pulmonary function (pulmonary hypertension). ECMO provides support of both the systemic and pulmonary ventricles and circulations. VADs are limited to support the ventricles. IABP supports both ventricles (increasing the diastolic pressure and perfusing the coronary arteries by means of balloon inflation) but mainly the left ventricle (reducing afterload during LV ejection by means of balloon deflation). ECMO and VADs are today the most prevalent means of mechanical circulatory assistance for children with congenital heart disease.

Necessity is the mother of invention, and because our institution has no ECMO or VAD program, it forced us to use IABP in children for more than a decade. The present report chronicles the largest pediatric IABP experience in cardiac surgical patients. To the best of our knowledge, our series comprises the youngest patients and the patients with the smallest BW in the world literature who survived IABP.

The $75 \%$ survival (ie, successful weaning off) after IABP support in our series compares favorably with the reported survival in adults, as well as with that seen in other pediatric series (Table 5). ${ }^{3,5,9-11}$

Infants tend to do worse than children on IABP (IABP survival: $70 \%$ vs $78.5 \%$, respectively, in our series). Pinkney and associates ${ }^{11}$ reported survival of $50 \%$ (4/8) in infants versus $66.7 \%(14 / 21)$ in children older than 1 year. However, as in our series, the difference in survival between infants and children was not statistically significant.

Although IABP is a quite different modality of mechanical circulatory support compared with ECMO, VADs, or both, we would attempt a rough comparison of their characteristics and results (Table E1). 
Survival of patients with congenital heart disease undergoing ECMO (according to the Extracorporeal Life Support Organisation registry ${ }^{12}$ ) ranged from $36 \%$ (neonates, up to 30 days) to $40 \%$ (children, $1-16$ years) and $42 \%$ (infants, 31 days-1 year). In 2 recent single-center studies, survival of pediatric cardiac surgical patients admitted to the ICU was $40 \% .^{13,14}$

Survival after LV assist device support in the series by Del Nido and coworkers ${ }^{15}$ was $71 \%$ (5/7) in infants with ALCAPA syndrome and severely compromised LV function. It is worth noting that all 5 survivors required reexploration for bleeding from the cannulation site.

The Extracorporeal Life Support Organisation Registry Report Data (July 2004) on patients started on some form of extracorporeal life support (with ECMO or VADs) show a $58 \%$ survival of the extracorporeal life support and $43 \%$ survival to discharge from hospital or transfer to transplantation in children $57 \%$ and $38 \%$ in neonates, respectively). ${ }^{16}$ These results are definitely no better than those achieved with the IABP support.

The timing of IABP in our series ranged from before weaning off $\mathrm{CPB}$ up to 7 days postoperatively, highlighting the difficulty in decision making. The most important index is the clinical judgment of the surgeon on LV performance. In our series we have introduced IABP insertion before attempting to wean off $\mathrm{CPB}$ in cases involving preoperatively known poor LV function, as in patients with ALCAPA syndrome. ${ }^{17}$ Our first patient with ALCAPA syndrome was easily weaned off CPB after repair but 36 hours later had clinically and hemodynamically deteriorated and had to be started on IABP with a good and prompt response. Since then, we have started all our patients with ALCAPA syndrome on IABP before attempting to wean them off CPB. ${ }^{6}$ The results (survival, $83.3 \%$ [5/6]) justified this aggressive policy. Of course, not all patients with ALCAPA syndrome need IABP support, but we would recommend prophylactic use of IABP in patients with preoperatively known severe LV dysfunction, using as criteria the degree of LV dilatation and the grade of the subsequent mitral valve regurgitation, as well as the clinical status of the patient.

Initiation of IABP in the theater, before attempting to wean off $\mathrm{CPB}$, seemed to result in a better, although not statistically significant, survival in our series when compared with initiation after failure to wean off CPB or in the ICU. Chaturvedi and associates ${ }^{13}$ also noticed a better survival when ECMO was begun in the theater than in the ICU (64\% vs 29\%, respectively), whereas Morris and cowork$\mathrm{ers}^{14}$ reported no difference.

In our series we used standard ECG timing methods for IABP inflation and deflation. Pinkney and associates ${ }^{11}$ have used an echocardiographic timing technique as a more accurate method of balloon timing with aortic valve closure and opening. Although there is a theoretic background in the concept of the echo-timing technique (radial artery tracing might deviate up to $120 \mathrm{~ms}$ from the central aortic pressure tracing), the method of IABP timing does not seem to make a difference in the effectiveness of IABP support because in the above-mentioned report it is stated that "survival was not statistically better in the echocardiography-time era as compared with the standard ECG triggered timing era." We had no major problems in effectively supporting our patients with the ECG-triggered timing method, and our results confirm this.

In our early experience we have used IABP after the Fontan (or Glenn) procedure, but it was followed by a high incidence of failure to retrieve poor ventricular function: 4 (57\%) of 7 patients were weaned off IABP (3 [43\%] were discharged from the hospital). Similar experience has been reported by others ${ }^{11,18-20}$ : of 16 patients undergoing the Fontan procedure, only 4 (25\%) were successfully weaned off IABP. Pinkney and associates ${ }^{11}$ recommend that "IABP should be used in this group only when the patient has primarily ventricular dysfunction rather than the low cardiac output state typically seen due to Fontan physiology...." Theoretically, IABP might benefit the single-ventricle physiology by reducing afterload and end-diastolic and filling pressures of the single ventricle. In fact, IABP seems not to be as beneficial as expected in the Fontan procedure, possibly because the causes of failure in Fontan physiology are multiple (eg, long-standing ventricular volume overload, increased pulmonary vascular resistance, and residual cardiac defects). We have abandoned the deployment of IABP for support of patients undergoing the Fontan procedure for several years. Our practice is that if the Fontan procedure does not work, we take it down and go back to the previous stage of bidirectional Glenn shunt.

Complications from IABP did appear in 3 patients in our series (in 2 they were severe). Others have reported no major complications caused by IABP resulting in fatality or IABP removal..$^{9-11}$ We had no complications in infants, in whom the balloon was inserted through the ascending aorta without the guide wire.

In conclusion, IABP has been proved to be an effective and life-saving adjunct to conventional medical treatment for cardiac support in properly selected pediatric cardiac surgical patients with refractory low cardiac output. Although not a substitute for ECMO or VADs, in centers with limited resources (eg, those in emerging countries), IABP can be an alternative for effective mechanical circulatory support. It can be used in children of all ages and, in fact, of all BWs with safety and with satisfactory early and longterm results. In neonates and small infants IAB insertion through the ascending aorta eliminates the risk of complications. In selected patients with preoperatively known se- 
vere LV dysfunction, there is a place for prophylactic use of IABP.

\section{References}

1. Moulopoulos SD, Topaz S, Kolff WJ. Diastolic balloon pumping (with carbon dioxide) in aorta: mechanical assistance to failing circulation. Am Heart J. 1962;63:669-75.

2. McEnany T, Kay H, Buckley M, Daggett W. Clinical experience with intraaortic balloon pump in 728 patients. Circulation. 1978;58(suppl I): $124-32$

3. Pollock JC, Charlton MD, Williams WG, Edmond J, Trusler GA. Intraaortic balloon pumping in children. Ann Thorac Surg. 1980;29: 522-8

4. Patel NC, Jothi M, Trivedi DB, et al. Post-cardiotomy mechanical circulatory support using a conventional bypass circuit in children. Eur $J$ Cardiothorac Surg. 2001;20:811-5.

5. Akomea-Agyin C, Kejriwal NK, Franks R, Booker PD, Pozzi M. Intraaortic balloon pumping in children. Ann Thorac Surg. 1999;67: 1415-20.

6. Pandey R, Ciotti G, Pozzi M. Anomalous origin of the left coronary artery from the pulmonary artery: results of surgical correction in five infants. Ann Thorac Surg. 2002;74:1625-30.

7. Booker PD. Intraaortic balloon pumping in young children. Pediatr Anesth. 1997;7:501-7.

8. Veasy LG, Blalock RC, Orth JL, Boucek MM. Intraaortic balloon pumping in infants and children. Circulation. 1983;68:1095-100.

9. Veasy LG, Webster HW, McGough EC. Intra-aortic balloon pumping adaptation for pediatric use. Crit Care Clin. 1986;2:237-49.

10. Webster HW, Veasy LG. Intra-aortic balloon pumping in children. Heart Lung. 1985;14:548-55.
11. Pinkney KA, Minich LL, Tani LY, Di Russo GB, Veasy LG, McGough EC. Hawkins JA. Current results with intraaortic balloon pumping in infants and children. Ann Thorac Surg. 2002;73:887-91.

12. Di Russo GB, Martin GR. Extracorporeal membrane oxygenation for cardiac disease: no longer a mistaken diagnosis. In: Jonas RA, editor. Seminars in thoracic and cardiovascular surgery, pediatric cardiac surgery annual 2005. St Louis: Elsevier Inc., p. 34-40.

13. Chaturvedi RR, Macrae D, Brown KL, et al. Cardiac ECMO for biventricular hearts after pediatric open heart surgery. Heart. 2004;90: 545-51.

14. Morris MC, Ittenbach RF, Godinez RI, et al. Risk factors for mortality in 137 pediatric cardiac intensive care unit patients managed with extracorporeal membrane oxygenation. Crit Care Med. 2004; 32:1061-9.

15. Del Nido PJ, Duncan BW, Mayer JE Jr, Wessel DL, LaPierre RA, Jonas RA. Left ventricular assist device improves survival in children with left ventricular dysfunction after repair of anomalous origin of the left coronary artery from the pulmonary artery. Ann Thorac Surg. 1999;67:169-72.

16. Cohen G, Permut L. Decision making for mechanical cardiac assist in pediatric cardiac surgery. In: Jonas RA, editor. Seminars in thoracic and cardiovascular surgery, pediatric cardiac surgery annual 2005. St Louis: Elsevier Inc., p. 41-50.

17. Pozzi M, Santoro G, Makundan S. Intraaortic balloon pump after anomalous origin of left coronary artery. Ann Thorac Surg. 1998;65: 555-7.

18. Nawa S, Sugawaqra E, Murakami T, Senoo Y, Teramoto S, Morita K. Efficacy of intra-aortic balloon pumping for failing Fontan circulation. Chest. 1988;93:599-603.

19. Del Nido PJ, Swan PR, Benson LN, et al. Successful use of intraaortic balloon pumping in a 2-kg infant. Ann Thorac Surg. 1988;46:574-6.

20. Park JK, Hsu DT, Gersony WM. Intraaortic balloon pumping management of refractory congestive heart failure in children. Paediatr Cardiol. 1993;14:19-22. 
TABLE E1. Comparison of the 3 main modalities for acute circulatory support in children with congenital heart defects: ECMO, centrifugal VAD, and IABP

\begin{tabular}{llll}
\hline Characteristic & \multicolumn{1}{c}{ ECMO } & \multicolumn{1}{c}{ VAD } & IABP \\
\hline Biventricular support & Yes & Possible & No \\
Open sternum & No & Yes & No (yes, in neonates/small infants) \\
Anticoagulation & Yes (180-250) & Yes (160-200) & Usual, not necessary \\
Complications & Moderate & Lower & Lowest \\
Bleeding & Moderate & Higher & Lowest \\
Ease of use & High & Lower & Low \\
Duration of support & Days to weeks & Days to weeks & Days to weeks \\
Cost & High & Lower & Lowest \\
Survival to hospital discharge & $36 \%-40 \% *$ & $30 \%-40 \% \dagger$ & $60 \%-62 \% \ddagger$
\end{tabular}

ECMO, Extracorporeal membrane oxygenation; VAD, ventricular assist device; IABP, intra-aortic balloon pumping. ${ }^{*}$ Chaturvedi and coworkers. ${ }^{13} \dagger$ Cohen and Permut. ${ }^{16}+$ Derived from Pinkney and coworkers ${ }^{11}$ and the present series.

Appendix E1. Pediatric IAB specifications

\begin{tabular}{|c|c|c|c|c|c|c|c|}
\hline $\begin{array}{l}\text { Age of } \\
\text { patient } \\
\text { (y) }\end{array}$ & $\begin{array}{l}\text { Weight of } \\
\text { patient } \\
(\mathrm{kg})\end{array}$ & $\begin{array}{c}\text { IAB } \\
\text { volume } \\
\text { (mL) }\end{array}$ & $\begin{array}{c}\text { Stroke } \\
\text { volume } \\
(\mathrm{mL})\end{array}$ & $\begin{array}{c}\text { Catheter } \\
\text { size (F) }\end{array}$ & $\begin{array}{c}\text { IAB } \\
\text { length } \\
\text { (cm) }\end{array}$ & $\begin{array}{c}\text { IAB } \\
\text { diameter } \\
(\mathrm{mm})\end{array}$ & $\begin{array}{c}\text { IAB } \\
\text { preload } \\
(\mathrm{mL})\end{array}$ \\
\hline$<1$ & $3-8$ & 2.5 & $5-10$ & 4.5 & 10.7 & 6.0 & 6 \\
\hline $1-2.5$ & 8-13 & 5.0 & $10-18$ & 5.5 & 12.8 & 8.0 & 10 \\
\hline $2.6-5$ & $13-18$ & 7.0 & $18-28$ & 5.5 & 14.2 & 9.0 & 12 \\
\hline 6-12 & $18-40$ & 12.0 & $28-68$ & 7.0 & 17.8 & 10.0 & 17 \\
\hline$>12$ & $>40$ & 20.0 & $68-90$ & 7.0 & 19.4 & 12.0 & 26 \\
\hline
\end{tabular}

$I A B$, Intra-aortic balloon. 